\title{
Gradient Echo T2*-weighted MR Findings of Diabetic Chorea and Ballismus
}

\author{
Yoshiharu Taguchi, Shutaro Takashima and Kortaro Tanaka
}

Key words: diabetic chorea and ballismus, gradient echo $\mathrm{T} 2 *$-weighted image, petechial hemorrhage

(Inter Med 49: 1045-1046, 2010)

(DOI: 10.2169/internalmedicine.49.3445)
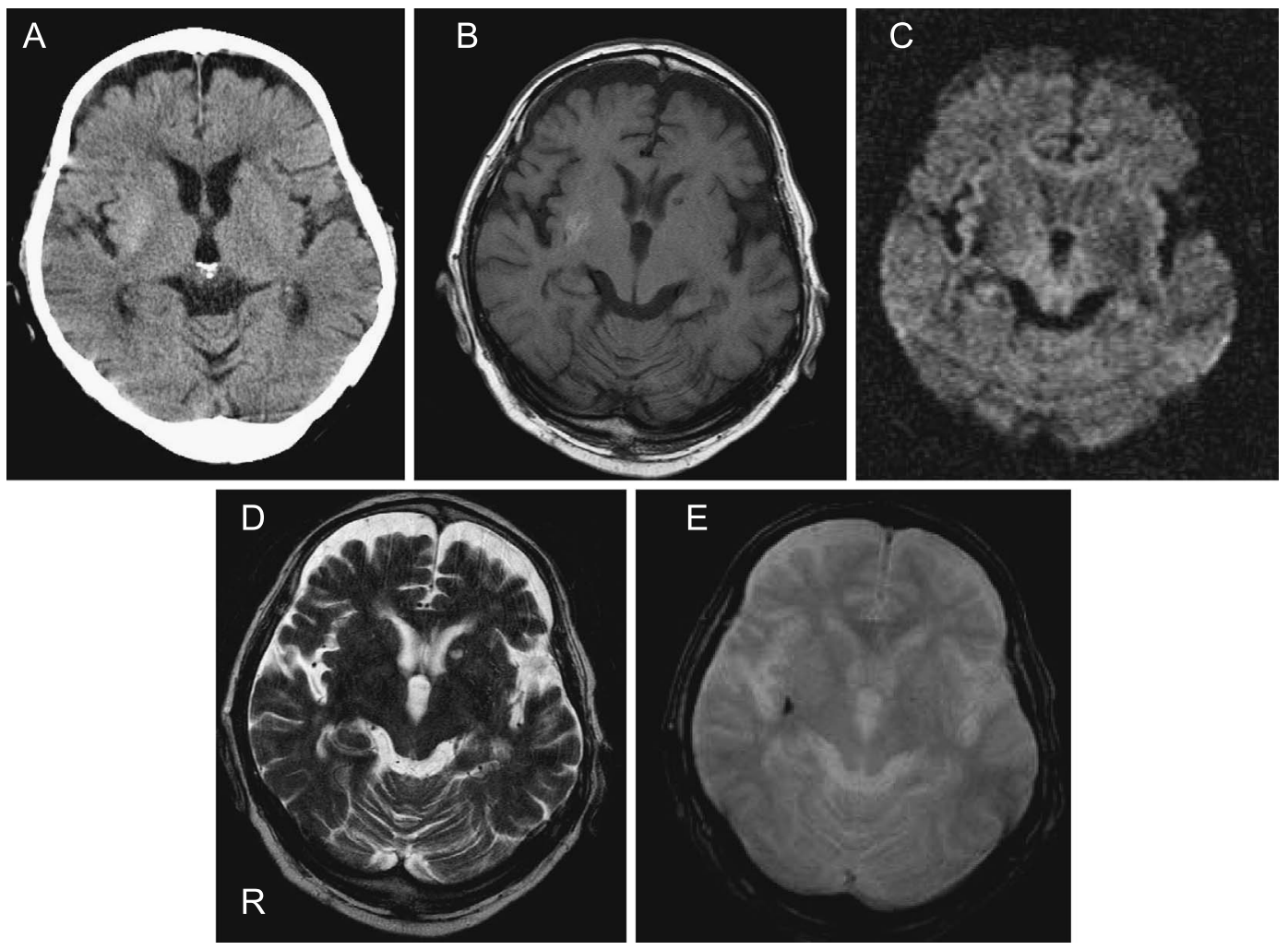

Picture 1. Brain computed tomography (A) on admission showed high densities in the right putamen. Brain MR, performed on the 13th day after admission, revealed a high signal intensity on a T1-weighted image (B) in the right putamen, and a low signal intensity on DWI (C), T2weighted (D) and gradient echo $\mathrm{T} 2 *$-weighted images (E).

A 76-year-old man had suddenly developed involuntary movement in his left arm, which had been gradually aggravated. He was admitted to our hospital twelve days after onset. He had no past history of diabetes mellitus, hypertension, cerebral infarction, parkinsonism or other neurologic disease. On neurologic examination, he was alert with normal cranial nerves. Although his muscle strength and deep tendon reflexes in all extremities were normal, he showed an involuntary movement like chorea and ballismus in his left arm. On admission, the blood glucose level was $348 \mathrm{mg} / \mathrm{dL}$, hemoglobin A1c was $15.1 \%$ and plasma osmotic pressure was $308 \mathrm{mOsm} / \mathrm{kg}$. Brain computed tomography (Picture $1 \mathrm{~A}$ ) showed high densities in the right putamen. He was diagnosed as having diabetic chorea and ballismus. 
Brain MR (Picture 1B-E), performed on the 13th day after admission, revealed high signal intensity on a T1-weighted image in the right putamen, and low signal intensity on DWI, T2- weighted and gradient echo T2*-weighted images.

It is well known that hemichorea-hemiballismus can result from non-ketotic hyperglycemia in diabetes mellitus. However, the pathophysiology of diabetic chorea and ballismus is still undetermined. Although striatal hyperintensity on T1- weighted images has been pointed out, there have been only a few reports on gradient echo $\mathrm{T} 2 *$-weighted imaging in patients with diabetic chorea and ballismus $(1,2)$. A low signal intensity on $\mathrm{T} 2 *$ sequences in part of the putamen could reveal more apparently a petechial hemorrhage with hemosiderin deposition in patients with diabetic chorea and ballismus.

\section{References}

1. Suto Y, Mori M, Kagimoto H, Saito J. A case of hemichorea with hyperglycemia presenting with low signal intensity in the striatum on $\mathrm{T} 2 *$-weighted gradient-echo magnetic resonance imaging. Rinsho Shinkeigaku (Clin Neurol) 44: 86-90, 2004 (in Japanese).
2. Abe Y, Yamamoto $T$, Soeda $T$, et al. Diabetic striatal disease: Clinical presentation, neuroimaging, and pathology. Intern Med 48: 1135-1141, 2009.

(C) 2010 The Japanese Society of Internal Medicine http://www.naika.or.jp/imindex.html 